\title{
Proceeding
}

Supplementary Issue: Winter Conferences of Sports Science. Costa Blanca Sports Science Events, 22-23 March 2021. Alicante, Spain.

\section{Plyometric training on sand versus grass: Effects on sprinting, jumping, agility and balance in soccer players}

\author{
VALERIO BONAVOLONTÀ, ROBERTO CARVUTTO $\triangle$, ANGELO DI GIOIA, MICHELE DE CANDIA \\ School of Medicine, Department of Basic Medical Sciences, Neuroscience and Sense Organs, University of \\ Study of Bari "Aldo Moro", Bari, Italy
}

\begin{abstract}
Soccer is an intermittent high-intensity activity requiring explosive strength and power production by the neuromuscular system. Plyometric training is recognized as an effective method for improving both sprinting and jumping ability through the stretch-shortening cycle. The aim of this study was to compare the effects of plyometric training on sand versus a grass surface on sprinting, jumping, agility, balance ability in soccer players. Sixteen adult soccer players volunteered in the study and were randomly assigned to a plyometric training group performed on sand (PS, $n=8$ ) or on grass (PG, $n=8$ ). Both groups performed 7 weeks of plyometric training on two separate weekly sessions lasting about 1.5 hour. Five-, 10 - and 20 -meters sprint test, Sargent test and standing long jump test, Illynois Agility test and Stork test were administered to assess sprinting, jumping, agility and balance ability, respectively. After 7 weeks of intervention results showed significative improvements in PS group for sprinting $(p<.05)$, for standing long jump test $(p<.05)$ and for balance $(p<.05)$. Small but not significant differences were found for the other variables. A 7-week plyometric training performed on sand showed improvements on sprinting, jumping and balance respect to the same training performed on grass surface in adult soccer players.

Keywords: Plyometric training; Soccer; Sand; Sprinting; Jumping; Balance.
\end{abstract}

Cite this article as:

Bonavolontà, V., Carvutto, R., Di Gioia, A., \& De Candia, M. (2021). Plyometric training on sand versus grass: Effects on sprinting, jumping, agility and balance in soccer players. Journal of Human Sport and Exercise, 16(3proc), S1104-S1113. https://doi.org/10.14198/jhse.2021.16.Proc3.27

Corresponding author. School of Medicine, Department of Basic Medical Sciences, Neuroscience and Sense Organs, University of Study of Bari "Aldo Moro", Lungomare Starita 1/b, 70132, Bari, Italy.

E-mail: roberto.carvutto@uniba.it

Abstract submitted to: Winter Conferences of Sports Science. Costa Blanca Sports Science Events, 22-23 March 2021. Alicante, Spain.

JOURNAL OF HUMAN SPORT \& EXERCISE ISSN 1988-5202.

(c) Faculty of Education. University of Alicante.

doi:10.14198/jhse.2021.16.Proc3.27

S1104 | 2021| Proc3|VOLUME 16

(c) 2021 University of Alicante 


\section{INTRODUCTION}

Soccer is an intermittent high-intensity activity whose actions require explosive strength and power production by the neuromuscular system (Impellizzeri et al., 2008). The performance of a footballer during a match requires numerous maximal and high-intensity ballistic muscle actions, such as jumps, passes, shots, contrasts, changes of direction, sprints and rapid changes of pace (Bangsbo et al., 2006; Ramirez-Campillo et al., 2014, 2015). Indeed, the most crucial moments of a soccer game such as gaining possession of the ball, scoring, assisting, preventing goals, etc., depend on players' ability to perform high-speed tasks and energy production (Sohnlein et al., 2014; Vaczi et al., 2013).

In line with the above mentioned physiological and performance demands, soccer training requires great attention on lower limbs muscular power training. In addition, movements such as vertical jumps or changes of direction in stable or unstable conditions are essential components of soccer athletic performance. These actions are characterized by muscular actions that occur in the so-called stretch-shortening cycle (SSC). During the SSC, pre-activated muscles undergo a rapid lengthening (eccentric phase) followed by an immediate shortening action (concentric phase), using the elastic energy stored during the eccentric (Michailidis et al., 2013).

Plyometric training (PT) is recognized as an effective method for improving both sprinting and jumping ability through the SSC. This type of work, through the performance of explosive bodyweight resistance exercises, improves physical abilities such as speed, strength and power (Booth and Orr, 2016). PT results in performance improvements for sprint times over distances between 5 and $40 \mathrm{~m}$, for maximal strength and muscle power, especially that of the hamstrings extensors, and for sport-specific agility (Váczi et al., 2013; Booth and Orr, 2016). PT has been also extensively applied to adolescents (Latino et al., 2019), to young athletes across different sports disciplines (Fischetti et al., 2019a; 2019b; Greco et al., 2019; Sannicandro et al. 2014) and in special populations sports (Fischetti et al., 2019c).

Plyometrics is an effective, quick, and easy sport-specific training methodology for improving training strategy in youth soccer and has been shown to produce improvements in jumping and sprinting performance (Komi, 2003; Markovic and Mikulic, 2010; Saez de Villarreal et al., 2015). For this reason, PT is considered an appropriate methodology to achieve improvements in the soccer-related performance, mainly attributable to neuromuscular adaptations (Chaouachi et al., 2014; Meylan et al., 2014; Ramirez-Campillo et al., 2015). Indeed. there is a general consensus that PT improves sport-specific skills such as agility, direction changes, body acceleration and deceleration movements, vertical jump performance and muscle power (Booth et al., 2016; Chimera et al., 2004; Sivakumar, 2017).

Several studies analysed PT performed on different non-traditional surfaces like sand. Compared to PT on stable, traditional surfaces, sand running has a higher energy cost and a lower impact training stimulus (Gaudino et al., 2013; Impellizzeri et al., 2008; Pinnington and Dawson, 2001). In particular, running on sand requires 1.2 to 1.6 times more energy expenditure than running on a stable surface (Gaudino et al., 2013; Pinnington and Dawson, 2001) and produces a significantly higher level of muscle activation (Pinnington, et al., 2005) and 2 to 3 times higher lactate accumulation (Pinnington and Dawson 2001). In addition, the high shock-absorbing qualities of sand reduce the impact forces of exercise, limiting the degree of exerciseinduced muscle-tendon damage, muscle soreness and any subsequent decrease in performance (Impellizzeri et al., 2008; Miyama and Nosaka, 2004). 
These proper characteristics of sand training have recently been applied to team sports. Studies have been conducted and compared the benefits, which different types of conditioning on stable and unstable surfaces can bring to sport performance (Binnie et al., 2013a, 2013b). Interval running on sand resulted in significantly greater heart rate (HR) and blood lactate (BLa) responses (Kumar 2016); however, similar levels of muscle damage, inflammation and soreness were recorded between the two surfaces, with no differences in performance on the following day (24 hours later) (Binnie et al., 2013a). Similar results were observed for a sport-specific conditioning session comprising high-intensity sprints, repeated sprints and agility exercises, as well as short-field games (Binnie et al., 2013b), suggesting that sandy surfaces can produce a higher intensity workout without adversely affecting post-exercise recovery over the following 24 hours. These results show that maximum intensity sprints with higher energy expenditure and metabolic power values can be performed on sand, without reaching maximum speed and with lower impact shocks. When soccer players were subjected to exercises involving changes of direction on this surface, it was noted that they reached values of deceleration values. In addition, sprinting on sand potentially involves limited stretching of the muscles involved. It can therefore offer a valid alternative to traditional training programs (Gaudino et al., 2013). Indeed, plyometric exercise on sand, because of the lower impact induced on the muscular-skeletal system, is a valid training for injury prevention, compared to other surfaces, reducing stress during intense training periods and it is also a valid support during rehabilitation and return to activity (Impellizzeri, et al., 2008). (Ramirez-Campillo et al., 2013) compared the strength results obtained from a 7 -week, twice-weekly plyometric workout performed on a stable surface such as a wooden gym floor and a $3 \mathrm{~cm}$ thick athletic mat. However, their results were inconsistent with respect to the effects of the training surface. Indeed, several studies found little benefit from using unstable surfaces. Arazi et al. (2014) observed that sand training improved agility and strength compared to plyometric training on a stable surface and (Impellizzeri et al., 2008) noted not only benefits in sprinting and jumping abilities, but also less onset of muscle pain. It could be then argued that PT on sand could be incorporated and used as a viable alternative both during the preparation period and during the course of the season (Váczi et al., 2013). A recent study by RamirezCampillo and colleagues (2020) reported greater PT effects on jumping due to multiple and varied training surfaces compared to a single type of training surface in young soccer players.

Anyway, it is not fully understood if PT performed on sand induce greater effects on different physical fitness components involved in soccer performance.

Therefore, aim of the present study was to compare the effects of a 7-weeks PT performed on grass versus sand on sprinting, jumping, agility and balance in soccer players.

\section{METHODS}

\section{Participants and procedures}

Sixteen male players (mean age, $24.4 \pm 5$ years) were recruited from a local club for the present study. Subject were randomly assigned to a grass PT group (PG, $n=8$ ) or sand PT group (PS, $n=8)$. All subjects were healthy and signed written informed consent to participate in the study.

All participants underwent two familiarization tests in the 2 weeks prior to the data collection. Baseline tests were carried out in the first 2 weeks of the preparatory period and were repeated after 7 weeks of training. The test protocol included a 5-, 10- and 20-meters sprint test, agility tests for change of direction (Illynois test), vertical and long jumping (Seargent test, standing long jump) and balance ability (Stork test). The measurements were carried out by an expert operator on the same day and under the same experimental conditions. All participants were engaged in two weekly training sessions supervised by the athletic trainer 
and a research member from the beginning until the end of the of the preparatory period of the season. Each training sessions lasted about 90 minutes and started with a 15-minute activation, followed by a 25 -minute specific PT workout (see Table I), always supervised by the same trainer.

\section{Testing procedures}

The sprint test started with a standardized 20-minute warm-up. Participants performed the 5, 10 and $20 \mathrm{~m}$ sprint tests from a standing position. Three tests separated by 6-8 min recovery were performed and the best results were recorded.

For the Sargent test the participant stands next to a centimetre pole and marks with his fingers the highest point he can reach, while standing sideways, with the same upper limb extended upwards, from a standing position. He then jumps upwards, performing a countermovement combined with the momentum of his upper limbs, to touch the highest possible point on the measuring stick. At the end of the jump, the height reached is measured.

Standing long jump: the participant jumps with both feet at the same height from the starting line with both legs together, performing a countermovement jump combined with the momentum of the upper limbs. At the end of the jump, the distance from the starting line to the heel of the subject is measured.

Illynois test (Figure 1) must be performed at maximum speed and in the shortest possible time. The participant starts at the bottom left cone, runs in a straight line, circles the top left cone, descends to the bottom cone in the middle row and slaloms around the outward and return cones, heads straight for the top right cone, circles it and finishes at the bottom right.

The Stork Static Balance Test was performed with participants standing on the dominant leg and resting the opposite foot against the inside of the knee. On the tiptoe, the participant had to maintain the balance position for as long as possible.

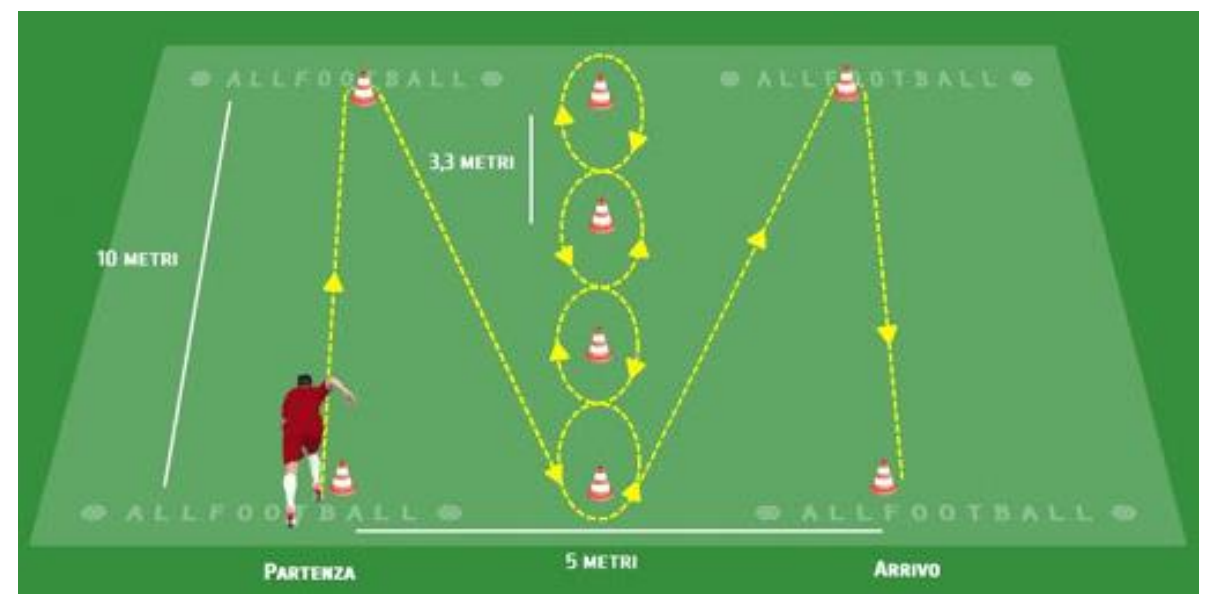

Figure 1. Representation of the Illynois Agility Test.

\section{Plyometric training}

Both plyometric groups underwent the same training program twice a week for 7 consecutive weeks. PG performed plyometric training on a grass field and PS on dry sand; on these days they replaced 25 minutes of their standard technical-tactical skills training with plyometric work. 
The plyometric training program for PG and PS group consisted of three main workshops where the volume load was progressively increased across the experimental intervention:

- Workshop $1=6$ lateral $0.3 \mathrm{~m}$ hurdle jumps ( 3 to left and 3 to right), then sprinting $10 \mathrm{~m}$.

- Workshop $2=6$ horizontal jumps ( 3 to left and 3 to right), then sprinting $10 \mathrm{~m}$.

- Workshop $3=6 \times 0.4 \mathrm{~m}$ hurdle jumps, then sprinting $10 \mathrm{~m}$.

PT work out details are described in Table 1.

Table 1: PT details across the intervention.

\begin{tabular}{lcccc}
\hline Week & Workshop 1 & Workshop 2 & Workshop 3 & Total contacts \\
\hline 1 & $6 \times 3$ & $6 \times 3$ & $6 \times 3$ & 54 \\
2 & $6 \times 4$ & $6 \times 4$ & $6 \times 4$ & 72 \\
3 & $6 \times 4$ & $6 \times 4$ & $6 \times 4$ & 72 \\
4 & $6 \times 5$ & $6 \times 5$ & $6 \times 5$ & 90 \\
5 & $6 \times 5$ & $6 \times 5$ & $6 \times 5$ & 90 \\
$6-7$ & $6 \times 6$ & $6 \times 6$ & $6 \times 6$ & 108 \\
\hline
\end{tabular}

\section{Statistical analysis}

All the data obtained from the pre-intervention tests were first compared and then the values obtained by the same group in their pre- and post-intervention. Considering a $95 \%$ confidence level or $a=.05$, using the Shapiro-Wilk test it was seen that the distribution for the variables 5- 10- and 20 meters sprint, long and vertical jump, agility and balance was not normal. Given the non-normal distribution the non-parametric Kruskall-Wallis test was used to check for statistical differences between groups for each dependent variable. When a statistical significance between groups for any dependent variable was detected, a two-tailed MannWhitney test was applied to verify which groups showed the differences. Statistical significance was set at $p$ $<.05$. Data analysis was performed with SAS statistical package.

\section{RESULTS}

After 8 weeks of training, comparing the averages obtained by the different groups in the pre- and postintervention of all the tests, the group that performed plyometric training on sand (PS) showed greater improvements in the 5, 10 and $20 \mathrm{~m}$ sprint times ( $z$ value $=2.2014,=2.2014,=1.8869$ respectively; $p<.05$ ), in the Stork balance test $(z$ value $=2.2014, p<.05)$ and in the long jump ( $z$ value $=2.0226, p<.05)$, compared to the group that performed plyometric training on the field (PG). The values obtained in the Illynois agility test and in the Sargent test values did not show statistical difference although slightly lower mean values were recorded for PS than for PG ( $p>.05)$.

\section{DISCUSSION AND CONCLUSIONS}

Soccer is a situational and intermittent sport with several components underpinning the performance (Raiola and Altavilla, 2020). Aim of the present study was to compare the effects of 7 weeks of PT performed on different surfaces on sprinting, jumping, agility and balance.

The main results of the study show that soccer players who underwent PT on sand showed greater improvements in 5, 10 and 20 m sprint times and static balance than what observed on a grass field for PG. However, other studies with different samples and PT intensity did not always observe the same benefits. 
The role of an unstable surface such as sand on the response to PT is still debated. Arazi et al. (2014) proposed that a consequent decrease in ground reaction time, with an increase in lateral movement and balance could increase biomechanical learning, neuromuscular adaptations (Markovic \& Mikulic, 2010) and strengthen the muscles involved in stabilization, thus enhancing the training response view on solid ground. Indeed, when jumping on the sandy surface, the foot drops into the sand, causing the athlete to activate additional force to perform subsequent jumps, and this training over time appears to improve strength.

Several researchers have pointed out the potentially favourable influence of training on an unstable surface on balance and agility (Arazi et al. 2014; Granacher et al., 2015), thus offering specific training for those competitions where one has to play on uneven and soggy fields. However, depending on the age, maturity and training status of athletes, the likelihood of the sandy surface correcting some overtraining may also be due to the increase in muscle strength compared to tapering a standard plyometric regime (de Lacey J. et al., 2014). In support of this idea, Impellizzeri et al. (2008) noted that when their plyometric training programs were conducted on sand, muscle soreness was reduced and Miyama and Nisoka (2004) found similar results.

It could be explained that the increases in sprint performance in both plyometric groups in our study reflect increases in muscle strength and power (Granacher et al., 2015; Ramírez-Campillo et al., 2013).

Similarly, Negra et al. observed rather similar improvements in sprinting after football players performed 8 weeks of plyometric training on an unstable or stable surface (Negra et al., 2017).

The difference observed for PS and PG can be explained by the fact that athletes were in a period of physical preparation (pre-season) and had not yet reached their fitness peak.

The present study found no improvement in the ability to change direction quickly, an important asset for a soccer player, between training on sand compared to a firm surface.

Similarly, Granacher et al. (2015) observed similar improvements in change-of-direction ability in adolescent male football after 8 weeks of PT on stable or unstable surfaces. Any increase in the change-of-direction performance of PS compared to PG could be explained by the fact that athletes have to develop greater strength to overcome obstacles during exercise on a sandy surface. When jumping over sand, the foot sinks into the sand and the athlete has to exert additional force to perform a subsequent jump (Arazi et al., 2014; Granacher et al., 2015).

Over time, the body adapts to this increased demand, improving its strength through increased nerve conduction velocity, maximization of electromyography, improved intermuscular coordination, improved motor unit recruitment strategy and increased excitability of the Hoffman reflex ( $\mathrm{H}$ reflex), as well as by changes in muscle size and architecture and single fibre mechanics (Markovic and Mikulic, 2010; Prieske, O. et al., 2013; Ramírez-Campillo et al., 2013).

During a plyometric movement, muscles rapidly switch from an eccentric to a concentric contraction phase (Markovic, G., \& Mikulic, P. 2010). A shortened duration of the dampening phase takes advantage of stored elastic energy and the stretch reflex, allowing a greater than normal release of power during the concentric phase of the movement; perhaps, this phenomenon is enhanced more by PS than by P (Granacher et al., 2015; Impellizzeri, et al., 2008). 
In terms of jumping ability, results showed benefits in jumping performance only for the PS group in both vertical and long jump. Similarly, Negra (2017) saw similar improvements in standing long jump in adolescent football players on stable and unstable surfaces and Granacher (2015) actually found greater gains in jump height against movement in young male football players after 8 weeks of plyometric training on stable rather than unstable surfaces. Arazi et al. (2014) also found that long jump training on sand improved jump performance more than long jump training on a stable surface such as the ground. A number of previous studies have emphasized the benefits of balance training programmes and the unstable nature of the sand surface may be useful in developing this skill (Granacher et al., 2015; Negra et al., 2017).

PS improved Stork Balance test times compared to PG in this study; this difference may reflect the fact that PS training strengthened tendons and ligaments, thus improving balance test performance.

Negra et al. (2017) also observed improvements in the Stork Balance test in adolescent soccer players after 8 weeks of plyometrics on unstable surfaces, although another work (Granacher et al., 2015) found no significant difference in response in adolescent athletes between stable and unstable PT.

Moreover, as suggested by previous and more recent research, coordinative ability training could favour cognitive functions (Latino et al. 2021). For future research, it would be of interest to combine this well-known training effect with PT on different surface, in order to verify if reactivity, sprinting and jumping skills could be enhanced also through the cognitive and neuro-muscular domain.

In conclusion, PT performed on sand showed improved effects on determinant components of soccer sportspecific performance, suggesting that this surface can represent a valid methodology to optimize the effectiveness of training. Further research is needed to better explore if these effects are long lasting compared to traditional surfaces and if are more suitable to the game specific needs.

\section{REFERENCES}

Arazi, H., Mohammadi, M., \& Asadi, A. (2014). Muscular adaptations to depth jump plyometric training: Comparison of sand vs. land surface. Interventional Medicine and Applied Science, 6(3), 125-130. https://doi.org/10.1556/imas.6.2014.3.5

Bangsbo, J., Mohr, M., \& Krustrup, P. (2006). Physical and metabolic demands of training and matchplay in the elite football player. Journal of sports sciences, 24(07), 665-674. https://doi.org/10.1080/02640410500482529

Binnie, M. J., Dawson, B., Pinnington, H., Landers, G., \& Peeling, P. (2013 a). Effect of training surface on acute physiological responses after interval training. The Journal of Strength \& Conditioning Research, 27(4), 1047-1056. https://doi.org/10.1519/JSC.0b013e3182651fab

Binnie, M. J., Dawson, B., Pinnington, H., Landers, G., \& Peeling, P. (2013 b). Part 2: Effect of training surface on acute physiological responses after sport-specific training. The Journal of Strength \& Conditioning Research, 27(4), 1057-1066. https://doi.org/10.1519/JSC.0b013e3182651d63

Booth, M. A., \& Orr, R. (2016). Effects of plyometric training on sports performance. Strength \& Conditioning Journal, 38(1), 30-37. https://doi.org/10.1519/SSC.0000000000000183

Chaouachi, A., Othman, B. A., Hammami, R., Drinkwater, E. J., \& Behm, D. G. (2014). The combination of plyometric and balance training improves sprint and shuttle run performances more often than plyometric-only training with children. Journal of Strength and Conditioning. https://doi.org/10.1519/JSC.0b013e3182987059 
Chimera, N. J., Swanik, K. A., Swanik, C. B., \& Straub, S. J. (2004). Effects of plyometric training on muscle-activation strategies and performance in female athletes. Journal of Athletic Training, 39(1), 24.

de Lacey, J., Brughelli, M., McGuigan, M., Hansen, K., Samozino, P., \& Morin, J. B. (2014). The effects of tapering on power-force-velocity profiling and jump performance in professional rugby league players. The Journal of Strength \& Conditioning Research, 28(12), 3567-3570. https://doi.org/10.1519/JSC.0000000000000572

Fischetti, F., Cataldi, S., \& Greco, G. (2019 a). A combined plyometric and resistance training program improves fitness performance in 12 to 14-years-old boys. Sport Sciences for Health, 15(3), 615-621. https://doi.org/10.1007/s11332-019-00560-2

Fischetti, F., Cataldi, S., \& Greco, G. (2019 b). Lower-limb plyometric training improves vertical jump and agility abilities in adult female soccer players. Journal of Physical Education and Sport, 19(2), 12541261. https://doi.org/10.7752/jpes.2019.02182

Fischetti, F., Greco, G., Cataldi, S., Minoia, C., Loseto, G., \& Guarini, A. (2019 c). Effects of physical exercise intervention on psychological and physical fitness in lymphoma patients. Medicina (Lithuania), 55(7). https://doi.org/10.3390/medicina55070379

Gaudino, P., Gaudino, C., Alberti, G., \& Minetti, A. E. (2013). Biomechanics and predicted energetics of sprinting on sand: hints for soccer training. Journal of Science and Medicine in Sport, 16(3), 271275. https://doi.org/10.1016/i.jsams.2012.07.003

Granacher, U., Prieske, O., Majewski, M., Büsch, D., \& Muehlbauer, T. (2015). The role of instability with plyometric training in sub-elite adolescent soccer players. International Journal of Sports Medicine, 36(05), 386-394. https://doi.org/10.1055/s-0034-1395519

Greco, G., Patti, A., Cataldi, S., lovane, A., Messina, G., \& Fischetti, F. (2019). Changes in physical fitness in young female volleyball players after an 8-week in-season pilates training program. Acta Medica Mediterranea, 35(6), 3375-3381. https://doi.org/10.19193/0393-6384 20196531

Impellizzeri, F. M., Rampinini, E., Castagna, C., Martino, F., Fiorini, S., \& Wisloff, U. (2008). Effect of plyometric training on sand versus grass on muscle soreness and jumping and sprinting ability in soccer players. British journal of sports medicine, 42(1), 42-46. https://doi.org/10.1136/bjsm.2007.038497

Komi, P. V. (2003). Stretch shortening cycle. In P. V. Komi (Ed.), Strength and power in sport. Oxford: Blackwell Science. https://doi.org/10.1002/9780470757215

Kumar, C. S. (2016). Effect of land plyometric and sand plyometric training on selected physical and physiological variables among hockey players. International Journal of Physical Education, Sports and Health, 3(3), 540-544.

Latino, F., Cataldi, S., \& Fischetti, F. (2021). Effects of a Coordinative Ability Training Program on Adolescents' Cognitive Functioning. Frontiers in Psychology, 12, 60. https://doi.org/10.3389/fpsyg.2021.620440

Latino, F., Greco, G., Fischetti, F., \& Cataldi, S. (2019). Multilateral training improves body image perception in female adolescents. Journal of Human Sport and Exercise, 14(Proc4), S927-S936. https://doi.org/10.14198/ihse.2019.14.Proc4.55

Markovic, G., \& Mikulic, P. (2010). Neuro-musculoskeletal and performance adaptations to lowerextremity plyometric training. Sports medicine, 40(10), 859-895. https://doi.org/10.2165/11318370$000000000-00000$

Meylan, C., \& Malatesta, D. (2009). Effects of in-season plyometric training within soccer practice on explosive actions of young players. Journal of Strength and Conditioning Research. https://doi.org/10.1519/JSC.0b013e3181b1f330 
Michailidis, Y., Fatouros, I. G., Primpa, E., Michailidis, C., Avloniti, A., Chatzinikolaou, A., ... \& Leontsini, D. (2013). Plyometrics' trainability in preadolescent soccer athletes. The Journal of Strength \& Conditioning Research, 27(1), 38-49. https://doi.org/10.1519/JSC.0b013e3182541ec6

Miyama, M., \& Nosaka, K. (2004). Muscle damage and soreness following repeated bouts of consecutive drop jumps. Adv Exerc Sports Physiol, 10(3), 63-69.

Negra, Y., Chaabene, H., Sammoud, S., Bouguezzi, R., Mkaouer, B., Hachana, Y., \& Granacher, U. (2017). Effects of plyometric training on components of physical fitness in prepuberal male soccer athletes: the role of surface instability. The Journal of Strength \& Conditioning Research, 31(12), 3295-3304. https://doi.org/10.1519/JSC.0000000000002262

Pinnington, H. C., \& Dawson, B. (2001a). The energy cost of running on grass compared to soft dry beach sand. Journal of Science and Medicine in Sport, 4(4), 416-430. https://doi.org/10.1016/S14402440(01)80051-7

Pinnington, H. C., Lloyd, D. G., Besier, T. F., \& Dawson, B. (2005). Kinematic and electromyography analysis of submaximal differences running on a firm surface compared with soft, dry sand. European Journal of Applied Physiology, 94(3), 242-253. https://doi.org/10.1007/s00421-005-1323-6

Prieske, O., Muehlbauer, T., Mueller, S., Krueger, T., Kibele, A., Behm, D. G., \& Granacher, U. (2013). Effects of surface instability on neuromuscular performance during drop jumps and landings. European Journal of Applied Physiology, 113(12), 2943-2951. https://doi.org/10.1007/s00421-013$2724-6$

Raiola, G., \& Altavilla, G. (2020). Testing motor skills, general and special coordinative, in young soccer. $\begin{array}{lll}\text { Journal of Human Sport and Exercise, 15(2proc), S206-S212. } & \text { S }\end{array}$ https://doi.org/10.14198/ihse.2020.15.Proc2.11

Ramirez-Campillo, R, Alvarez, C, Garcia-Pinillos, F, Garcla-Ramos, A, Loturco, I, Chaabene, H, and Granacher, U. (2020). Effects of combined surfaces vs. single-surface plyometric training on soccer players' physical fitness. J Strength Cond Res 34(9): 2644- 2653. https://doi.org/10.1519/JSC.0000000000002929

Ramírez-Campillo, R., Gallardo, F., Henriquez-Olguín, C., Meylan, C. M., Martínez, C., Álvarez, C., ... \& Izquierdo, M. (2015). Effect of vertical, horizontal, and combined plyometric training on explosive, balance, and endurance performance of young soccer players. The Journal of Strength \& Conditioning Research, 29(7), 1784-1795. https://doi.org/10.1519/JSC.0000000000000827

Ramírez-Campillo, R., Álvarez, C., Henríquez-Olguín, C., Baez, E. B., Martínez, C., Andrade, D. C., \& Izquierdo, M. (2014). Effects of plyometric training on endurance and explosive strength performance in competitive middle-and long-distance runners. The Journal of Strength \& Conditioning Research, 28(1), 97-104. https://doi.org/10.1519/JSC.0b013e3182a1f44c

Ramírez-Campillo, R., Andrade, D. C., \& Izquierdo, M. (2013). Effects of plyometric training volume and training surface on explosive strength. The Journal of Strength \& Conditioning Research, 27(10), 2714-2722. https://doi.org/10.1519/JSC.0b013e318280c9e9

Saez de Villarreal, E., Suarez-Arrones, L., Requena, B., Haff, G. G., \& Ferrete, C. (2015). Effects of plyometric and sprint training on physical and technical skill performance in adolescent soccer players. Journal of Strength and Conditioning Research, 29, 1894-1903. https://doi.org/10.1519/JSC.0000000000000838

Sannicandro, I., Piccinno, A., Cofano, G., Eirale, C., Bisciotti, G.N. (2014). Effects of plyometric training on phases of jumping in young fencers, Med Sport, 67, 27-46.

Sohnlein, Q., Muller, E., \& Stoggl, T. L. (2014). The effect of 16-week plyometric training on explosive actions in early to mid-puberty elite soccer players. Journal of Strength and Conditioning Research, 28, 2105-2114. https://doi.org/10.1519/JSC.0000000000000387 
Váczi, M., Tollár, J., Meszler, B., Juhász, I., \& Karsai, I. (2013). Short-term high intensity plyometric training program improves strength, power and agility in male soccer players. Journal of human kinetics, 36(1), 17-26. https://doi.org/10.2478/hukin-2013-0002

\section{(c) $(7) \ominus$}

This work is licensed under a Attribution-NonCommercial-NoDerivatives 4.0 International (CC BY-NC-ND 4.0). 